\title{
The Blue Jay Bookshelf
}

BIRGER'S BIRDS. By Birger Roos. 1968. Golden Press, New York. \$1.50.

A tiny hard cover book containing 20 pictures in colour and each identified by common and scientic name. For example,

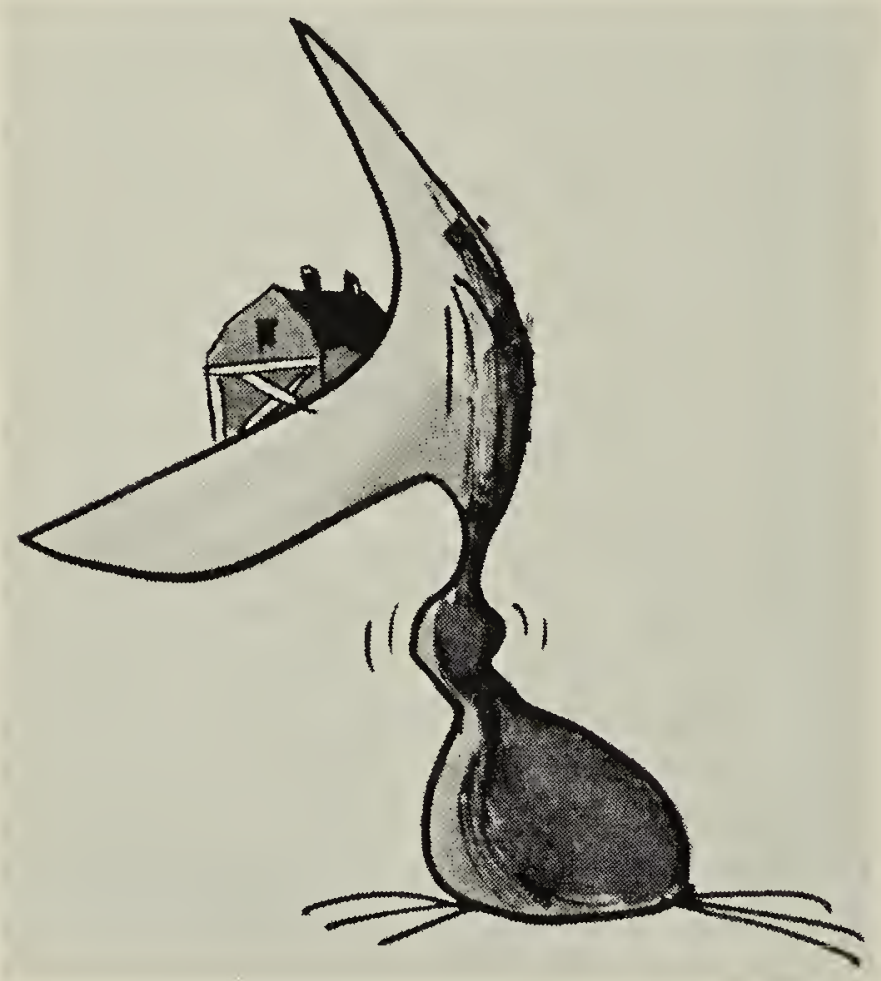

Barn Swallow

Hirundo mustica

AN ENVIRONMENT FIT FOR PEOPLE. By Raymond F. Dasmann. 1968. Public Affairs Pamphlet No. 421. Public Affairs Pamphlets, 381 Park Ave. S., New York. 25 cents.

People looking for inexpensive materials on conservation to distribute among students or members of other interested groups may be interested in this little 28-page booklet. It is of course written principally for Americans, but since our problems are so similar, Mr. Dasmann's comments are also relevant for us in Canada. He writes from the viewpoint of a new definition of conservation as "rational use of the environment to achieve the highest quality of living for mankind."

Much of the discussion is concerned with the hazards facing cities, but Dr. Dasmann, who is Director of Environmental Studies for The Conservation
Foundation and has worked with uni versities, foundations and UNESCC on conservation problems, also recog. nizes the interdependent needs o urban and rural area. Soil erosion exploitation of rangelands and forests destruction of the marine environ ment, and threats to our wildlife anc natural resources are all related $t$ his broad concern.

There are rates for larger quanti ties, and no shipping charges on pre paid orders, thus encouraging the wider circulation of this booklet Another title in the same Publi Affairs series that might be of in teresit is Edward Edelson's The battl for clean air. - Margaret Belcher Regina.

A PLACE FOR EVERYTHING. 1968 By David Munroe. CBC publication 122 pp., 387 photographs, nine full page plates. Available from CBC Winnipeg. Price $\$ 3.50$.

"A place for everything and every thing in its place," is an old saying and if some people forget this and liv in a state of chaos and muddle, th opposite is true in nature's scheme fo full utilization of her resources, an the proper distribution of her many and varied forms of plant and anima life.

This is well explained in the fore word of this fascinating book abou Canada, which is at once a simpl explanation of ecology, a travelogu from a new and exciting point 0 view, a gallery of fine, self-explana tory photographs, and a well-sustaine plea for better understanding of Cana dian wildlife in relation to humar exploitation. The Arctic regions, th mountains, the eastern woodlands, th northern forests, the great plains, an the sea-girt coastal islands are al dealt with understandingly, and wit? great appreciation. This colorful bool should go far towards bringing abou a better sense of the wholeness of ou far-flung country for those who, un 
ble or unwilling to travel, may have ended towards a merely regional iewpoint; as well as for those who, ven when they do travel, may tend to etain that regional point of view and hus make biased comparisons.

Certainly, maple groves in the glory of fall are breathtakingly beautiful; ut so are great prairies at sunset, he mountains with their glittering eaks and cool, shadowed rivers, while he "blue fragrance" of which a oetess wrote can be found in the onely land of ice-floes lit by the midight sun. Yet all these scenes of eauty would seem lifeless, and perlaps sad, were it not for the flash of blue jay's wing, the passing of wildowl overhead, the whistle of a mounain marmot, or the calling of ptarmian, not to mention the sight of even rander beasts. It may not be appreiated by many Canadians that nowhere outside of Africa are there to e seen herds of hoofed animals in lumbers comparable to our barrenround caribou in their migrating ordes. All this, and much more, will e found within the pages of this olume.

Everything is in its place - but for low long?

Exploitation by man threatens many nvironments, and therefore many pecies of plants, and animals and ish; and this is brought to the eader's attention in simple and easily inderstood terms, to the end that each nd every Canadian may pause to onsider his or her personal responsiility.

The CBC is to be doubly congratuated on having produced this work; irst for its clearly uttered mesisage, and secondly for its artistic presentaion of wildlife and scenery. This book hould bring a new sense of identity o young readers, as well as a sense f delight to older and more sophistiated people.-R. D. Symons, Silton.

MANITOBA WILDFLOWERS, 1968. Manitoba Department of Mines \& Vatural Resources, Conservation Ex- tension Branch, Winnipeg, Manitoba. 25 pp., illus. in color. Free.

Although this is only a 25-page booklet, it compares very well for colour photography and layout with publications like the National Geographic.

The Introduction admits that this booklet is not an identification guide but a little colour introduction to the many flowers to be found in Manitoba. In addition to the beautiful photos, however, there are many small items of interest about these flowers. I was particularly interested by the little item on the Paintbrush, which 'we attempted to transplant last year. It promptly dried up and died. So we thought when we read the item which stated: "To flower it has to join its roots to the roots of other plants and absorb food from them," that the plant was parasitic. However, the Audubon Nature Encyclopedia states that it is sometimes parasitic, although it has a root system of its own. The 1969 issue of "Prairie Garden" has an extensive article on wildflowers. Therein it states that Paintbrush can definitely be transplanted, and that it will come up next spring even though it dried up immediately after being moved.-Anthony J. Hruska, Gerald, Saskatchewan.

WATER. 1968. Inland Waters Branch, Dept. of Energy, Mines and Resources, Govt. of Canada, Ottawa. 60 pp., illust. Available free of charge.

The formula $\mathrm{H}_{2} \mathrm{O}$ gives a simple chemical definition of a colorless, transparent, tasteless, scentless compound of oxygen and hydrogen in liquid state, convertible by heat into steam and by cold into ice. It is also the only substance that gets lighter in weight as it turns into solid form.

However, water is not that simple or pure any more. Water such as "heavy water" and "tritiated water" have appeared. Finally, we have the hazard of "polluted water."

This booklet contains important information on water and water use. Concise explanations are given of the 
hydrologic cycle of desalination, conservation, and water resources.

Because of the intrinsic importance of Canadian water a short review of the International Hydrologic Decade (IHD) is in order. On January 1, 1965 the Educational, Scientific and Cultural Organization of the UN instituted a ten-year program of study and research into the fundamental principles affecting water distribution and movement throughout the world. Canada has been taking a very active part in this program. Canada is in a unique position because of its hydrologic environments which vary from Arctic, temperate, humid, to desert.

Canada has a major portion of the world's total supply of fresh water. Therefore, any program of research into the supply and movement of water would be incomplete without Canada's participation. In recognition of the scope of the proposed Canadian program, Canada was appointed to a two-year term (1965-6) as a member of the Co-ordinating Council, this term being extended later for a second two-year term.

As naturalists we are interested in conservation of our heritage. Conservation is a simple concept but very difficult to apply. Who can assign a dollar value to the flowers that grow on the side of a hill, or the birds that inhabit our marshes? True conservation must rest on a very fine balance. On the one hand there must be a balance between many different uses; on the other hand, between aesthetic values and material needs.-Anthony J. Hruska, Gerald.

WHOOPING CRANES. 1969. U.S. Dept. of the Interior, Fish and Wildlife Service, Resource Publication \# 75. U.S. Govt. Printing Office, Washington, D.C. 20402. Price 10 cents.

The Blue Jay has tried to keep its readers informed of publications on Whooping Cranes, since these rare birds migrate throughout the Great Plains area which the journal serves. For that reason, we want to mention a little French-fold type of bulletin that has just been published by the U.S. Fish and Wildlife Service to give the latest information on the current status of the species. For 1968 the total of adult and young birds in the wild is given at 50, with 19 additional birds in captivity.

A summary statement of the physical character, life history, and status of the species is made, and there are accompanying black-andwhite photographs and an outline map that relates the breeding and wintering grounds in Wood Buffalc National Park and the Aransas $\mathrm{Na}$ tional Wildlife Refuge.

The two-year experiment (1967. 1968) of removing eggs from nests ir the wild for hatching at the Patuxent Research Centre in Maryland is de. scribed, and it is urged that the taking of eggs does not reduce the normal number of young of the yea raised to maturity in the wild. Th eggs hatched in captivity are there fore expected to increase the tota crane population.

Credit is given in the bulletin to the National Audubon Society for spon soring research and protection for the Whooping Crane.-The Editors.

HIN'TERLAND WHO'S WHO. 1968 By the Canadian Wildlife Service Queen's Printer, Ottawa.

Under the popular title of "Hinter land Who's Who" there has just ap peared a series of folder-type pam phlets published by the Canadiar Wildlife Service on the Canadia fauna. We have had sent to us th following pamphlets-Bats, The Can ada goose, White-tailed deer, Th whooping crane, Red fox, The blac. bear, Herring gull, The caribou, an we assume that anyone interested ca get these by writing to the Queen' Printer, Ottawa.

Each folder contains a quick sketc of the animal, with a note on rang and habitat, a brief reading list, an the inevitable final paragraphs o how the Canadian Wildlife Service fit "into the national wildlife picture."The Editors. 